\title{
Differential Mechanism for Differentiation into Immunoglobulin-secreting Cells in Human Resting B Lymphocyte Subsets Isolated on the Basis of Cell Density
}

\author{
Noboru Suzuki, Yuji Ueda, and Tsuyoshi Sakane \\ Third Division, Department of Internal Medicine, Shimane Medical University, Izumo, Shimane 693, Japan
}

\begin{abstract}
We have investigated differential mechanism for differentiation of human peripheral blood resting $B$ cells to Ig-secreting cells. Purified resting $B$ cells were further fractionated into subsets by discontinuous density gradients of Percoll, and proliferation and differentiation responses to Staphylococcus aureus Cowan I (SAC) and/or T cell-derived soluble factors were studied.

High density resting $B$ cells were stimulated to proliferate vigorously in response to $\mathrm{SAC}$, but were poorly differentiated by SAC in presence of $T$ cell factors. In contrast, low density resting $B$ cells failed to proliferate in response to $S A C$ and/or T cell factors; these cells could, however, be induced by stimulation with SAC plus $T$ cell factors to become cells actively secreting Ig. These results indicate that there may exist heterogeneity in the human resting $B$ cells: one subset of resting B cells (B cells with low density) can differentiate directly into Ig-secreting cells without the need for proliferation, and another subset (B cells with high density) can proliferate actively without subsequent differentiation into Ig-secreting cells.

To address whether these resting $B$ cell subsets belong to the same lineage, only high density $B$ cells recovered from circulating resting $B$ cells were first stimulated for $7 \mathrm{~d}$ with SAC, refractionated on Percoll gradients, and differentiation response of the refractionated $B$ cells to $S A C$ and $T$ cell factors was examined. B cells shifting toward low density fraction were located in the resting status and could differentiate in response to SAC plus $\mathrm{T}$ cell factors. These results indicate that some of $B$ cells with high density belong to the same cell lineage as those with low density and they must first proliferate before differentiation.
\end{abstract}

\section{Introduction}

In the past several years, there has emerged a new conceptual framework for viewing the mechanism by which resting B lymphocytes are activated during an antigenic encounter, and the proliferation and differentiation events occur after the initial stages of activation (1-5). Although never explicitly stated, the framework can be readily outlined in animal $(1,2)$ as well as human models (3-5). Resting B cells become activated via

Address all correspondence and reprint requests to Dr. T. Sakane, Third Division, Department of Internal Medicine, Shimane Medical University, Izumo, Shimane 693, Japan.

Received for publication 22 May 1987 and in revised form $17 \mathrm{Au}$ gust 1987.

J. Clin. Invest.

(c) The American Society for Clinical Investigation, Inc.

0021-9738/88/01/0261/09 \$2.00

Volume 81, January 1988, 261-269 cross-linking of membrane Ig receptors by affinity-purified anti-Ig antibodies or Ig cross-linking materials such as Staphylococcus aureus Cowan I (SAC) ${ }^{1}$ as polyclonal analogs for antigen (6-9), or via occupancy of membrane Ig receptors by antigens and cognate $T$ cell interactions involving the Ia antigens of resting B cells (10-12). Activation of resting B cells via either mechanism results in functional expression of receptors for soluble proliferation and/or differentiation factors (1-5, 13-15), so that a major fraction of B cells that once are activated can be driven through proliferation and differentiation to Ig secretion solely with aid of the appropriate soluble factors (1-5, 13-15). However, it has remained an area of controversy whether the proliferation event is a prerequisite to the $B$ cell differentiation, without which subsequent responsiveness to soluble differentiation factors and maturation to Ig-secreting cells do not occur (16-19), or alternatively, whether after the initial activation of B cells, some, but not all, of the B cells could directly mature to Ig-secreting cells without undergoing the proliferation event $(4,20-31)$.

In the present studies, we have addressed these questions using human $B$ cell subsets separated by a centrifugation of Percoll discontinuous density gradient. B cell subsets were cultured with SAC in presence or absence of $\mathrm{T}$ cell-derived soluble factors, and their proliferation and Ig production measured. We have found that $(a)$ some subsets of resting B cells (that sediment in a low density fraction) can not proliferate in response to SAC and/or soluble factors, but rather directly differentiate into Ig-secreting cells in presence of SAC plus soluble factors; $(b)$ another subsets of resting B cells (that sediment in a high density fraction) can be induced by SAC or SAC plus soluble factors to proliferate vigorously, but not to differentiate effectively into Ig-secreting cells; and $(c)$ these high and low density B cells could belong at least in part to the same cell lineage because stimulation of the high density $B$ cells by SAC causes some of them to transit to the low density $B$ cells, which in turn differentiate into Ig-secreting cells in response to SAC plus soluble factors.

\section{Methods}

Cell separations. Peripheral blood mononuclear cells from healthy volunteer donors were separated into $T$ cells and non- $T$ cells by means of a sheep red blood cell-rosette technique. B cells were obtained by further depletion of $T$ cells remaining in the non- $T$ cell fraction by complement-mediated cell lysis with OKT3 monoclonal antibody (Ortho Pharmaceutical, Raritan, NJ). This was followed with depletion of monocytes by removal of cells adhering to petri dishes and by complement-mediated cell lysis with OKM1 monoclonal antibody (Ortho Pharmaceutical). Ali these purification procedures were repeated twice and have been described in detail elsewhere $(32,33)$.

The resultant B cell population contained no $\mathrm{T}$ cells, $<0.2 \%$ cells

1. Abbreviations used in this paper: Ara-C, cytosine arabinoside; $\mathrm{PFC}$, plaque-forming cell; SAC; Staphylococcus aureus Cowan I. 
reactive with OKM5 monoclonal antibody (Ortho Pharmaceutical), and $>90 \%$ cells bearing surface-membrane Ig. Moreover, the B cells obtained did not respond at all to PHA (Wellcome Research Laboratories, Wellcome Reagent Ltd., Beckenham, England) and Con A (Pharmacia Fine Chemicals, Div. of Pharmacia Biotechnology International AB, Uppsala, Sweden) even if cultures were performed at high enough cell density $\left(1 \times 10^{5}\right.$ cells/well) and optimal mitogen concentrations (PHA, $1 \mu \mathrm{g} / \mathrm{ml}$; Con A, $10 \mu \mathrm{g} / \mathrm{ml}$ ). Mean \pm SE counts per minute of unstimulated B cells, PHA-stimulated B cells, and Con A-stimulated B cells from 16 different normal donors were $772 \pm 120,726 \pm 136$, and $730 \pm 112$, respectively.

Monocytes were obtained by collecting the non-T cells adhering firmly to petri dishes. Monocyte preparations consisted of $>95 \%$ cells that were reactive with OKM5 antibody.

Preparation of partially purified $T$ cell-derived soluble factors. Peripheral blood mononuclear cells from different healthy subjects $(2.5$ $\left.\times 10^{6} / \mathrm{ml}\right)$ were stimulated for $48 \mathrm{~h}$ with PHA $(1 \mu \mathrm{g} / \mathrm{ml})$. The supernatants were collected and purified by several chromatographic steps as described elsewhere $(34,35)$. In brief, after ultrafiltration, the supernatants were concentrated by $\left(\mathrm{NH}_{4}\right)_{2} \mathrm{SO}_{4}$ precipitation, subsequently further purified by $\left(\mathrm{NH}_{4}\right)_{2} \mathrm{SO}_{4}$ fractionation, and then dialyzed. The dialyzed active material was passed over an anion-exchange chromatographic column (DEAE-Sepharose). Helper factor activity that can drive activated $B$ cells to proliferate and to secrete Ig eluted as a broad peak centered at $\sim 0.07 \mathrm{M} \mathrm{NaCl}$. The helper factor-containing material was further purified using gel filtration with Ultrogel, and sequential polyacrylamide gel electrophoresis containing SDS. The resultant material was designated partially purified $\mathrm{T}$ cell-derived soluble factors. The characterization of the factors obtained has been described previously $(34,35)$. The factors obtained had neither PHA activity, IL-1 activity, or interferon $\gamma$ activity; they contained B cell growth factor activity and B cell differentiation factor activity as well as IL-2 activity when measured by using an assay system as described elsewhere $(32,33)$.

Density gradient separation of $B$ cells. B cells were further separated by centrifugation on discontinuous Percoll density gradients according to the method of Dagg et al. $(36,37)$. Briefly, $5 \times 10^{7}-15 \times 10^{7} \mathrm{~B}$ cells, suspended in $2.5 \mathrm{ml}$ of $30 \%$ Percoll (Pharmacia Fine Chemicals) were layered onto the gradients ranging from 45 to $60 \%$ Percoll in $5 \%$ increments of $2.5 \mathrm{ml}$ in $15-\mathrm{ml}$ centrifuge tubes (Iwaki Glass, Tokyo, Japan). The gradients were centrifuged at $3,000 \mathrm{~g}$ for $5 \mathrm{~min}$ at $4^{\circ} \mathrm{C}$. Cells at each interface were removed with a pasteur pipette. The layer between 45 and $50 \%$ Percoll is the low density fraction; between 50 and $55 \%$, the intermediate density fraction; and between 55 and $60 \%$, the high density fraction.

Assay for proliferative responses of $S A C$-stimulated B cell subsets. 5 $\times 10^{4} \mathrm{~B}$ cells of individual fractions were stimulated with various concentrations of SAC, but usually $0.002 \% \mathrm{vol} / \mathrm{vol}$, for various periods of time in presence or absence of partially purified $\mathrm{T}$ cell-derived soluble factors ( $25 \% \mathrm{vol} / \mathrm{vol})$. Triplicate cultures in 96-well round-bottomed microtiter plates (Costar Data Packaging Corp., Cambridge, MA) were performed in a total volume of $200 \mu$ and incubated at $37^{\circ} \mathrm{C}$ in a humidified atmosphere of $5 \% \mathrm{CO}_{2} / 95 \%$ air. Proliferative responses were measured by the incorporation of [methyl- $\left.{ }^{3} \mathrm{H}\right]$ thymidine $(5 \mathrm{Ci} /$ mmol; Amersham Corp., Arlington Heights, IL) over the last $20 \mathrm{~h}$ of the culture $(32,33)$.

Assay for plaque-forming cell (PFC) responses of SAC-stimulated B lymphocyte subsets. The culture to induce Ig-secreting cells was established in a $1-\mathrm{ml}$ vol in $12 \times 75 \mathrm{~mm}$ plastic tubes (Falcon Labware Div., Becton-Dickinson \& Co., Oxnard, CA) with $2 \times 10^{5}$ fractionated B cells, various concentrations of SAC (usually $0.002 \% \mathrm{vol} / \mathrm{vol}$ ), and 400 $\mu \mathrm{l}$ partially purified $\mathrm{T}$ cell-derived soluble factors. The triplicate cultures were incubated for various periods of time. Cells were then harvested, washed three times in Hanks' balanced salt solution, and assayed for number of IgM-producing cells. Number of IgM-producing cells was detected in a reverse hemolytic PFC assay (38) and the results were expressed as the mean of $\mathrm{PFC} / 10^{6} \mathrm{~B}$ cells in the original culture $(32,39)$.
In certain experiments, $B$ cells sedimenting in the high density layer were stimulated by SAC for 3 or $7 \mathrm{~d}$. Thereafter, these stimulated B cells were again applied onto the Percoll density gradients and fractionated according to their density. These refractionated B cells were then tested for their proliferative and PFC responses to the stimulation with SAC and/or T cell factors. In other experiments, cultures assayed for proliferation and differentiation of fractionated $B$ cells were set in presence of DNA synthesis inhibitor, cytosine arabinoside (Ara-C), to evaluate the role of replication of B cells played in their terminal maturation (see below).

Cell staining. Cell staining with monoclonal antibodies and data analysis were performed as previously described, with certain modifications (40). Cells were incubated with aggregated human IgG (Sigma Chemical Co., St. Louis, MO) for $45 \mathrm{~min}$ at $37^{\circ} \mathrm{C}$ (to prevent $\mathrm{Fc}$ fragment binding), washed, and allowed to react with optimal concentrations of mouse monoclonal antibodies, OKT3, OKM1, OKT9 (antibody to transferrin receptors; Ortho Pharmaceutical), anti-Tac, and anti-B1 (Coulter Diagnostics, Coulter Electronics, Inc., Hialeah, FL). Fluorescein-conjugated $\mathrm{F}\left(\mathrm{ab}^{\prime}\right)_{2}$ fragment of affinity-purified goat antimouse IgG (Tago, Inc., Burlingame, CA) was then used as a developing antibody. Cells were also directly stained with fluorescein-conjugated $\mathrm{F}\left(\mathrm{ab}^{\prime}\right)_{2}$ fragment of goat anti-human $\operatorname{Ig}(\mu, \delta$, and $\mu+\gamma+\alpha$ chains) obtained from Cappel Laboratories, Cochranville, PA. Stained cells were analyzed by flow microfluorimetry using a FACStar (B-D FACS System, Mountain View, CA) or a Ortho Spectrum III (Ortho Diagnostic Systems, Inc., Raritan, NJ).

Inhibitor. Wide range of concentrations of DNA synthesis inhibitor Ara-C $(0.5-0.005 \mu \mathrm{g} / \mathrm{ml})$ was used (41). Ara-C was added to cell cultures, at dosage described, in the beginning of culture, and maintained in the cultures throughout the culture period. At the end of culture, cell viability was always estimated by trypan blue dye exclusion and expressed as the ratio of number of viable cells at the end of culture to number of cells in original culture.

\section{Result}

Characterization of $B$ lymphocyte subsets separated by Percoll density gradient centrifugation. Purified B lymphocytes were fractionated on Percoll discontinuous density gradients. The relative cell number distribution of $B$ lymphocytes in each gradient fraction was as follows: $5 \pm 3 \%$ of the B cells sedimented in the layer between 30 and $45 \%$ Percoll, $15 \pm 7 \%$ in the layer between 45 and $50 \%$ Percoll, $48 \pm 11 \%$ in the layer between 50 and $55 \%$ Percoll, and $30 \pm 8 \%$ in the layer between 55 and 60\% Percoll (each value represents the mean from 12 normal subjects \pm SD).

The relative size of cells (cell diameter) within the B cell subsets as compared with the average size of the total B lymphocyte population was calculated from the forward-angle light scatter analysis using FACStar, and the results are summarized in Table I. With a transition from the higher density fraction to the less dense fraction of Percoll discontinuous density gradients, there was a progressive increase in cell size; cells sedimenting in the layer between 55 and $60 \%$ Percoll (high density fraction) and those, in the layer between 45 and $50 \%$ Percoll (low density fraction) were of small and large B cells, respectively.

Mostly, all B cells sedimenting into the high density fraction (fraction between 55 and 60\% Percoll) expressed both IgM and IgD on their surfaces; in contrast, they did not express at all OKT9 and Tac antigens on the surfaces, both of which are known to be markers of activated B cells $(40,42,43)$ (Table I). There was increasing proportion of surface $\mathrm{IgM}^{+}, \mathrm{IgD}^{-} \mathrm{B}$ cells with a transition into less dense fractions (Table I). However, $\mathrm{OKT}^{+}{ }^{+}$and/or $\mathrm{Tac}^{+} \mathrm{B}$ cells were not detectable even among 
Table I. Characteristics of B Cell Subsets Separated by Percoll Density Gradient Centrifugation*

\begin{tabular}{|c|c|c|c|c|c|c|c|c|c|c|c|c|}
\hline \multirow[b]{3}{*}{ Fraction } & \multicolumn{6}{|c|}{ Surface markers } & \multirow{3}{*}{$\begin{array}{l}\text { Cell size by } \\
\text { forward- } \\
\text { angle light } \\
\text { scatter }\end{array}$} & \multirow{3}{*}{$\begin{array}{l}\text { Surface } \\
\text { IgM }^{+} D^{-} / \\
\text {IgM }^{+} D^{+}\end{array}$} & \multirow{3}{*}{$\begin{array}{l}\text { Spontaneous } \\
\text { proliferation }^{\ddagger}\end{array}$} & \multirow{3}{*}{$\begin{array}{l}\text { Proliferation } \\
\text { in response } \\
\text { to } T \text { cell } \\
\text { factors }\end{array}$} & \multirow{2}{*}{\multicolumn{2}{|c|}{ Cell cycle analysis" }} \\
\hline & \multirow{2}{*}{$\begin{array}{l}\text { Surface } \\
\mathrm{Ig}^{+}\end{array}$} & \multirow[b]{2}{*}{$\mathrm{B1}^{+}$} & \multirow[b]{2}{*}{$\mathrm{OKT}^{+}$} & \multirow[b]{2}{*}{$\mathrm{OKM}^{+}$} & \multirow[b]{2}{*}{$\mathrm{Tac}^{+}$} & \multirow{2}{*}{$\begin{array}{l}\text { Transferrin } \\
\text { receptor }^{+}\end{array}$} & & & & & & \\
\hline & & & & & & & & & & & $\mathrm{G}_{0} / \mathrm{G}_{1}$ & $\mathrm{~S}+\left(\mathrm{G}_{2} / \mathrm{M}\right)$ \\
\hline & $\%$ & $\%$ & $\%$ & $\%$ & $\%$ & $\%$ & & & $\Delta c p m \times 10^{-3} /$ & $\times 10^{4}$ cells & \% & $\%$ \\
\hline \multicolumn{13}{|l|}{ High density } \\
\hline (55-60\%) & $>90$ & $>90$ & $<1$ & $<1$ & $<1$ & $<1$ & 25.3 & $<0.01$ & 0.4 & 0.4 & $>99$ & $<1$ \\
\hline \multicolumn{13}{|l|}{ Intermediate } \\
\hline density $(50-55 \%)$ & $>90$ & $>90$ & $<1$ & $<1$ & 1 & 1 & 33.3 & 0.02 & 0.3 & 0.5 & $>99$ & $<1$ \\
\hline \multicolumn{13}{|l|}{ Low density } \\
\hline$(45-50 \%)$ & $>90$ & $>90$ & $<1$ & $<1$ & 2 & 2 & 37.3 & 0.18 & 0.2 & 0.4 & $>99$ & $<1$ \\
\hline $30-45 \% * *$ & $>70$ & $>70$ & 1 & $<20$ & 2 & ND & 41.0 & 0.17 & 0.1 & 0.6 & $>99$ & $<1$ \\
\hline
\end{tabular}

* Results represent the mean of five experiments. ${ }^{*}$ Spontaneous proliferation was measured by the incorporation of $\left[{ }^{3} \mathrm{H}\right]$ thymidine during the 1 st $20 \mathrm{~h}$ of culture. ${ }^{8} \mathrm{~T}$ cell-derived soluble factors and $\left[{ }^{3} \mathrm{H}\right]$ thymidine were added to cultures of $\mathrm{B}$ cells, and proliferative responses were measured by the incorporation of $\left[{ }^{3} \mathrm{H}\right]$ thymidine during the following $20 \mathrm{~h}$. "Cell cycle analysis was performed by using ethidium bromide staining. ' $\Delta \mathrm{cpm}$ was calculated by subtracting background counts per minute (counts per minute of cultures containing medium alone) from counts per minute of cultures containing B cells with/without $\mathrm{T}$ cell-derived soluble factors. ${ }^{* *}$ A sufficient number of cells from a layer between 30 and 45\% Percoll was not available to measure the proliferation and differentiation responses by SAC in the following study, and thus, this fraction was not designated.

B cells sedimenting in the low density fraction (layer between 45 and 50\% Percoll) (Table I).

Cell cycle analysis of the B cell subsets was also performed. Preparations of B cell subsets were processed for cellular DNA analysis as described elsewhere $(39,44)$. B cell subsets were fixed with $99 \%$ ethyl alcohol, washed twice, and incubated at $37^{\circ} \mathrm{C}$ with RNase, $40 \mathrm{U} / \mathrm{ml}$, for $1 \mathrm{~h}(39,44)$. The cellular materials were then stained in a single step with a staining solution containing ethidium bromide, using the low-salt procedure described by Vindeløv (44). Thereafter, the materials were analyzed on an Ortho Spectrum III, and a minimum of 1 $\times 10^{4}$ cells were accumulated for each DNA histogram. It was shown that $>99 \%$ of the cells in each of all the fractions had accumulated in $G_{0} / G_{1}$ phase of cell cycle (Table I). The results indicate that even large $B$ cells (sedimenting in the less dense fraction) in peripheral blood are located in $G_{0} / G_{1}$ phase of cell cycle and do not enter $S$ phase. Regarding this point, we also measured spontaneous incorporation of $\left[{ }^{3} \mathrm{H}\right]$ thymidine by the individual $\mathrm{B}$ cell subsets during the $20 \mathrm{~h}$. No detectable amounts of $\left[{ }^{3} \mathrm{H}\right]$ thymidine incorporation were observed by cells in any fractions of Percoll density gradients (Table I). Moreover, addition of partially purified T cell-derived soluble factors (Table I) or recombinant IL-2 (Takeda Pharmaceutical Corp., Osaka, Japan) (data not shown) to the individual B cell subsets did not lead to blastic transformation of the B cells. The overall results presented here indicate that $B$ cells sedimenting in individual layers of Percoll discontinuous density gradients are resting B cells.

Proliferative responses of $B$ cell subsets to $S A C$. It has been generally accepted that SAC can activate resting $B$ cells in a polyclonal manner to undergo proliferation and, when provided with adequate $T$ cell-derived soluble factors, to maintain a proliferative state and secrete $\operatorname{Ig}(8,9)$. We have investigated which B cell subsets separated by centrifugation of Percoll discontinuous density gradients have a preferential ability to proliferate in response to SAC. To this end, $5 \times 10^{4} \mathrm{~B}$ cell subsets were stimulated for various periods with $0.002 \%$ SAC (Fig. 1). Peak incorporation of $\left[{ }^{3} \mathrm{H}\right]$ thymidine in both $B$ cells sedimenting in the high density fraction and those sedimenting in the intermediate density fraction was found at $3 \mathrm{~d}$ of culture; the magnitude of SAC-induced response by $\mathrm{B}$ cells in the high density fraction was much greater than that by B cells in the intermediate density fraction. In contrast, $B$ cells in the low density fraction consistently incorporated only little $\left[{ }^{3} \mathrm{H}\right]$ thymidine in response to SAC during $7 \mathrm{~d}$ of culture. Similar responsiveness pattern by B cell subsets was also observed over a wide range of SAC concentrations (data not shown). Thus, B cells sedimenting in higher density fractions can be contributing the cells that undergo proliferation in response to SAC. The above notion was further supported by the following findings. First, cell numbers recovered from the SAC-stimulated cultures of cells in the fraction of high density B cells were 16 $\times 10^{4}$ /original cultures; in the fraction of intermediate density B cells, $11 \times 10^{4}$; and in the fraction of low density B cells, 6

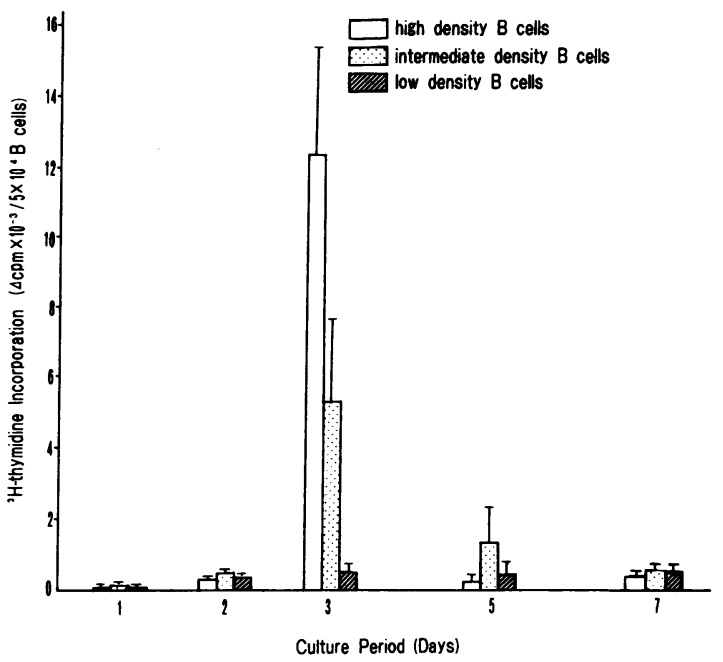

Figure 1. Proliferative responses of human peripheral blood B cell subsets fractionated on Percoll to SAC. $5 \times 10^{4}$ Percoll-fractionated $B$ cells were incubated for the indicated periods with SAC $(0.002 \%$ $\mathrm{vol} / \mathrm{vol}$ ), and proliferative responses were measured by incorporation of $\left[{ }^{3} \mathrm{H}\right]$ thymidine during the last $20 \mathrm{~h}$ of culture. $\Delta \mathrm{cpm}$ was calculated by subtracting counts per minute of unstimulated cultures from counts per minute of SAC-stimulated cultures. Data represent the mean $\Delta \mathrm{cpm}+\mathrm{SE}$ of four separate experiments using four different normal donors. 


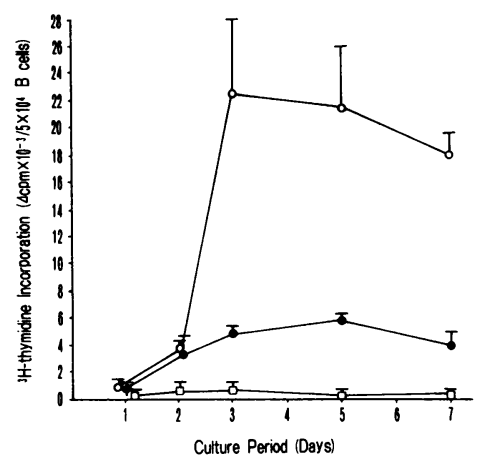

Figure 2. Proliferative responses of Percoll-fractionated B cells to SAC plus T cell-derived soluble factors. $5 \times 10^{4}$ Percoll-fractionated $B$ cells were cultured with SAC $(0.002 \% \mathrm{vol} / \mathrm{vol})$ in the presence of partially purified $\mathrm{T}$ cell-derived soluble factors $(25 \% \mathrm{vol} / \mathrm{vol})$ for the indicated periods, and proliferative responses were measured by incorporation of $\left[{ }^{3} \mathrm{H}\right]$ thymidine

during the last $20 \mathrm{~h}$ of culture. $\Delta \mathrm{cpm}$ was calculated by subtracting counts per minute of B cells alone from counts per minute of SAC plus $T$ cell factor-stimulated B cells. Data represent the mean $\Delta \mathrm{cpm}+\mathrm{SE}$ of four separate experiments using four different normal donors. $০$, High density B cells; ๑, intermediate density B cells; $\square$, low density B cells.

$\times 10^{4}$. The recovered $B$ cell numbers could reflect the difference in proliferative capacity of individual B cell subsets. Second, the proliferative response of the higher density B cells to SAC fell to background levels by day 5 of culture (Fig. 1). When $T$ cell-derived soluble factors were added at the beginning of SAC-stimulated culture, the proliferative state of the higher density B cells could be sustained even on day 7 (Fig. 2). Note here again that even in the presence of $T$ cell factors, low density B cells lack the ability to proliferate in response to SAC regardless of culture periods (Fig. 2).

$P F C$ responses of $B$ cell subsets to $S A C$ in presence of $T$ cell factors. The in vitro IgM-PFC responses to SAC in presence or absence of $\mathrm{T}$ cell-derived soluble factors were also examined for B cells in individual fractions. When SAC was added to B cells in absence of $\mathrm{T}$ cell factors, IgM-PFC responses were not induced at all in B cells from any fractions (data not shown). As shown in Fig. 3, the addition of both SAC and T cell factors to cultures of either B cells sedimenting in the low density fraction or those in the intermediate fraction resulted in considerable IgM-PFC responses; only marginal PFC responses, however, occurred in the B cells with high density. This was true regardless of SAC concentrations (data not shown) and culture periods (Fig. 3). These data suggest that there may exist differential activation mechanisms in B cell subsets. Small, high density resting $B$ cells preferentially proliferate in response to SAC in an antigen-mimic fashion; the bulk of these $B$ cells, however, can not be subsequently driven by SAC to differentiate into Ig-secreting cells even in presence of $T$ cell factors. On the contrary, although the cells in the fraction of large, low density resting B cells appear to lack the ability to proliferate in response to SAC regardless of presence of $\mathrm{T}$ cell factors, they can differentiate into Ig-secreting cells directly in response to SAC plus $\mathrm{T}$ cell factors.

To further characterize the possible role of proliferation in differentiation of the cells in the fraction of low density B cells to Ig-secreting cells, we added varying concentrations of DNA synthesis inhibitor Ara-C to cultures of B cell subsets. As noted in Table II, addition of $\geq 0.05 \mu \mathrm{g} / \mathrm{ml}$ of Ara-C resulted in complete abrogation of SAC-induced proliferation by cells in the fractions of high and intermediate density $B$ cells. The same concentrations $(\geq 0.05 \mu \mathrm{g} / \mathrm{ml})$ of Ara-C also completely

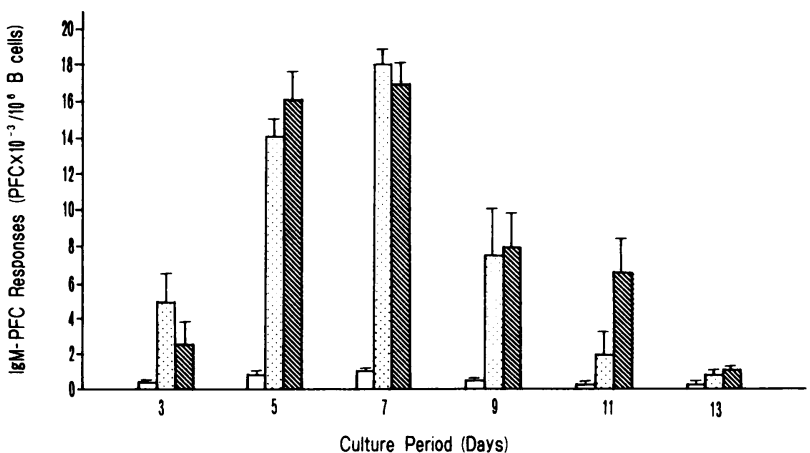

Figure 3. SAC-induced IgM-PFC responses by Percoll-fractionated B cells. $2 \times 10^{5}$ Percoll-fractionated B cells were stimulated with SAC $(0.002 \% \mathrm{vol} / \mathrm{vol})$ in the presence of partially purified $\mathrm{T}$ cell-derived soluble factors $(40 \% \mathrm{vol} / \mathrm{vol})$ for the indicated periods. The number of cells secreting IgM was measured using a reverse hemolytic PFC assay. Only IgM-PFC responses were measured because the Ig binding characteristics of staphylococcal protein A that SAC would display in an insoluble form to act, at least in part, as B cell activators, might interfere with reverse hemolytic PFC assay for IgG-producing cells $(5,32)$. The mean PFC responses $+\mathrm{SE}$ of four separate experiments using four different normal donors are shown. $\square$, High density B cells; $\square$, intermediate density B cells; 0 , low density B cells.

blocked the differentiation of intermediate density B cells. In contrast, SAC stimulation in presence of $\mathrm{T}$ cell factors induced considerable PFC responses by cells in the fraction of low density B cells even under influence of $0.05 \mu \mathrm{g} / \mathrm{ml}$ of Ara-C. Preferential cytotoxicity of Ara-C for cells in the fractions of higher density $B$ cells could not explain the above observations because there was no difference in cell viability recovered from cultures of low density B cells added at certain concentrations of Ara-C as compared with that recovered from cultures of high density $\mathrm{B}$ cells added at corresponding concentrations of Ara-C. The findings suggest that there may exist two types of B cell differentiation pathway as mentioned by Mayer (29): a proliferation-dependent pathway, analogous to the traditional scheme of B cell differentiation, and a proliferation-independent mechanism by which specific B cell subsets can be moved to terminal maturation phase without expansion of the $B$ cell clone.

Involvement of monocytes in $B$ cell proliferation and differentiation. Many previous observations have documented in literature $(2,45)$ that macrophage or macrophage product acts directly on B cells and plays a necessary role both in the proliferation of activated B cells and in the generation of Ig-secreting cells. These observations indicate that adding back of monocytes to SAC-stimulated B cell cultures may cascade for proliferation of low density B cells and for differentiation of high density B cells. To clarify this problem, autologous monocytes were introduced at a final concentration of $5 \%$ to SAC-stimulated cultures of B cell subsets. These cell mixtures were incubated in absence or presence of $\mathrm{T}$ cell factors, and the proliferative responses or PFC responses were measured on day 3 or 5 , respectively.

As shown in Table III, most of the high density B cells could not be driven to differentiate into Ig-secreting cells even in the presence of autologous monocytes. Also, low density B cells supplemented with autologous monocytes did not proliferate in response to SAC stimulation. These results further 
Table II. Effects of Ara-C on the Proliferation and Differentiation of SAC-stimulated B Cell Subsets*

\begin{tabular}{|c|c|c|c|c|c|}
\hline & \multirow[b]{2}{*}{ SAC } & \multirow[b]{2}{*}{ Ara-C } & \multicolumn{3}{|l|}{ B cell subsets } \\
\hline & & & $\begin{array}{l}\text { High density } \\
(55-60 \%)\end{array}$ & $\begin{array}{l}\text { Intermediate density } \\
(50-55 \%)\end{array}$ & $\begin{array}{l}\text { Low density } \\
(45-50 \%)\end{array}$ \\
\hline & & $\mu g / m l$ & & & \\
\hline \multirow{7}{*}{$\begin{array}{l}\text { SAC-induced proliferation }{ }^{\ddagger} \\
\qquad\left(\mathrm{cpm} \times 10^{-3} / 5 \times 10^{4} \mathrm{~B} \text { cells }\right)\end{array}$} & 0 & 0 & 0.2 & 0.2 & 0.2 \\
\hline & + & 0 & 14.7 & 5.2 & 0.6 \\
\hline & + & 0.5 & 0.1 & 0.2 & 0.2 \\
\hline & + & 0.05 & 0.5 & 0.4 & 0.2 \\
\hline & + & 0.005 & 5.3 & 3.7 & 0.5 \\
\hline & $\begin{array}{l}\mathrm{SAC}+\mathrm{T} \text { cell } \\
\text { factors }\end{array}$ & Ara-C & & & \\
\hline & & $\mu g / m l$ & & & \\
\hline \multirow{7}{*}{$\begin{array}{l}\text { SAC-induced differentiation } \\
\qquad\left(P F C \times 10^{-2} / 10^{6} \mathrm{~B} \text { cells }\right)\end{array}$} & 0 & 0 & 0 & 0 & 0 \\
\hline & + & 0 & 6 & 42 & 117 \\
\hline & + & 0.5 & 0 & 0.2 & 0 \\
\hline & + & 0.05 & 0.3 & 0.7 & 40 \\
\hline & + & 0.005 & 4 & 24 & 127 \\
\hline & $\begin{array}{l}\mathrm{SAC}+\mathrm{T} \text { cell } \\
\text { factors }\end{array}$ & Ara-C & & & \\
\hline & & $\mu g / m l$ & & & \\
\hline \multirow{5}{*}{$\begin{array}{l}\text { Cell viability" (viable cells at the end of culture } \\
\times 10^{-4} / 2 \times 10^{5} \text { cells in original culture) }\end{array}$} & 0 & 0 & 8.0 & 6.4 & 7.6 \\
\hline & + & 0 & 15.7 & 10.7 & 6.2 \\
\hline & + & 0.5 & 3.1 & 2.1 & 3.9 \\
\hline & + & 0.05 & 7.0 & 6.5 & 6.9 \\
\hline & + & 0.005 & 14.1 & 10.2 & 8.2 \\
\hline
\end{tabular}

* Varying concentrations of Ara-C were added to cultures assayed for proliferation and differentiation of $B$ cell subsets fractionated on Percoll during the entire period of culture. Values are the mean of five different experiments. ${ }^{\ddagger} \mathrm{B}$ cells were stimulated for $3 \mathrm{~d}$ with SAC $(0.002 \%$ $\mathrm{vol} / \mathrm{vol}$ ), and proliferative responses were measured by the incorporation of $\left[{ }^{3} \mathrm{H}\right]$ thymidine over the last $20 \mathrm{~h}$ of culture. ${ }^{\S} \mathrm{B}$ cells were cultured for $5 \mathrm{~d}$ with SAC plus T cell-derived soluble factors $(40 \% \mathrm{vol} / \mathrm{vol})$, and IgM-producing cells were measured in a reverse PFC assay. "B cells were cultured for $5 \mathrm{~d}$ with SAC plus $\mathrm{T}$ cell factors, and cell viability was estimated by trypan blue dye exclusion at the end of culture.

indicate that distinct functional properties of $B$ cell subsets reflect intrinsic characteristics of individual $B$ cell subsets and are not due to complete depletion of monocytes.

Relation of low density $B$ cells to high density $B$ cells. Because the above experiments demonstrated that B lymphocytes that undergo proliferation in response to SAC are, at least in part, different from those that do differentiation into Ig-secreting cells, it was of interest to determine whether low density B cells and high density B cells belong to the same cell lineage or to distinct cell lineages. To analyze the relationship between high and low density B cells in normal human peripheral blood, only high density B cells were first recovered by centrifugation of Percoll density gradients from freshly isolated B cells, stimulated for 3 or $7 \mathrm{~d}$ with SAC, and recentrifuged on Percoll density gradients. Thereafter, refractionated B cells were further incubated for $5 \mathrm{~d}$ with $\mathrm{SAC}$ and/or $\mathrm{T}$ cell factors, and measured for their PFC responses. As shown in Figs. 4 and 5 , cells originally sedimenting in the fraction of high density B cells showed a shift toward lesser density fractions after stimulation with SAC for 3 or $7 \mathrm{~d}$. Moreover, cells shifting toward the fraction of low density B cells after an incubation of high density B cells for $3 \mathrm{~d}$ with SAC could differentiate into Ig-secreting cells either in response to $T$ cell factors alone or in response to SAC plus T cell factors (Fig. 4). Note here that the B cells being moved to the low density fraction after SAC stimulation for $3 \mathrm{~d}$ can incorporate massive amounts of $\left[{ }^{3} \mathrm{H}\right]$ thymidine spontaneously (spontaneous incorporation of $\left[{ }^{3} \mathrm{H}\right]$ thymidine by low density $B$ cells derived from 3-d SAC stimulation of high density B cells in three normal subjects: $15,725 \pm 2,362 \mathrm{cpm}$ [mean $\pm \mathrm{SD}$ ]), so that they must have entered $S$ phase through $G_{1}$ progression. Probably, $T$ cell helper factors could drive the $B$ cells in the cell-cycle progression to differentiate into Ig-secreting cells without additional SAC stimulation. In contrast, only few cells shifting toward low density $B$ cells after an incubation of cells in the high density with SAC for $7 \mathrm{~d}$ differentiated into Ig-secreting cells in response to $\mathrm{T}$ cell factors alone (Fig. 5). Their differentiation required restimulation with SAC and T cell factors (Fig. 5) as has been observed in freshly isolated low density B cells. Here, the low density B cells derived from $7 \mathrm{~d}-\mathrm{SAC}$ stimulation of high density $B$ cells showed only little spontaneous $\left[{ }^{3} \mathrm{H}\right]$ thymidine incorporation during the $1 \mathrm{st} 20 \mathrm{~h}$ of culture as has also been observed in freshly isolated low density $\mathrm{B}$ cells (spontaneous incorporation of $\left[{ }^{3} \mathrm{H}\right]$ thymidine by low density $B$ cells derived from $7 \mathrm{~d}-\mathrm{SAC}$ stimulation of high density $\mathrm{B}$ cells in three normal subjects; $173 \pm 71 \mathrm{cpm}$ ). The above results suggest 
Table III. Role of Monocytes in the Proliferation and Differentiation of SAC-stimulated B Cell Subsets

\begin{tabular}{|c|c|c|c|}
\hline \multirow[b]{3}{*}{ B cell responses } & \multicolumn{3}{|c|}{ SAC-stimulated cultures } \\
\hline & \multirow[b]{2}{*}{$\begin{array}{l}\text { Addition of } \\
\text { monocytes }\end{array}$} & \multicolumn{2}{|l|}{ B cell subsets } \\
\hline & & $\begin{array}{l}\text { High density } \\
(55-60 \%)\end{array}$ & $\begin{array}{l}\text { Low density } \\
(45-50 \%)\end{array}$ \\
\hline Proliferation $*\left(\Delta \mathrm{cpm} \times 10^{-3} / 5\right.$ & 0 & $10.4 \pm 0.2$ & $0.3 \pm 0.1$ \\
\hline $\begin{array}{l}\times 10^{4} \mathrm{~B} \text { cells originally placed in } \\
\text { culture) }\end{array}$ & + & ND & $0.3 \pm 0.1$ \\
\hline $\begin{array}{l}\text { Differentiation into Ig-secreting } \\
\text { cells }{ }^{\ddagger}\left(\mathrm{IgM} \text {-PFC } \times 10^{-3} / 10^{6}\right. \\
\text { B cells originally placed in } \\
\text { culture) }\end{array}$ & $\begin{array}{l}0 \\
+\end{array}$ & $\begin{array}{l}0.8 \pm 0.2 \\
0.7 \pm 0.2\end{array}$ & $\begin{array}{l}17.8 \pm 0.5 \\
N D\end{array}$ \\
\hline
\end{tabular}

* $5 \times 10^{4}$ B cell subsets were stimulated for $3 \mathrm{~d}$ with SAC in presence or absence of $5 \%$ autologous monocytes. Proliferative responses were measured by incorporation of $\left[{ }^{3} \mathrm{H}\right]$ thymidine during the last $20 \mathrm{~h}$ of culture. $\Delta \mathrm{cpm}$ was calculated by subtracting counts per minute of unstimulated cultures from counts per minute of SAC-stimulated cultures. Data represent the mean $\Delta \mathrm{cpm} \pm \mathrm{SE}$ of four separate experiments using four different normal donors.

$\$ 2 \times 10^{5}$ B cell subsets supplemented with or without $5 \%$ autologous monocytes were stimulated with SAC in the presence of partially purified $\mathrm{T}$ cell factors for $5 \mathrm{~d}$. The number of cells secreting IgM was measured using a reverse hemolytic PFC assay. The mean PFC responses \pm SE of four separate experiments using four different normal donors are shown.

that a small population of SAC-induced Ig-secreting cells could originate from cells in the fraction of the high density $B$ cells, and thus, that cells in the fraction of high density B cells, at least in part, belong to the same cell lineage as those in the fraction of low density B cells.

Note here, however, that if one calculates simply number of the PFC on the basis of the data shown in Figs. 4 and 5,
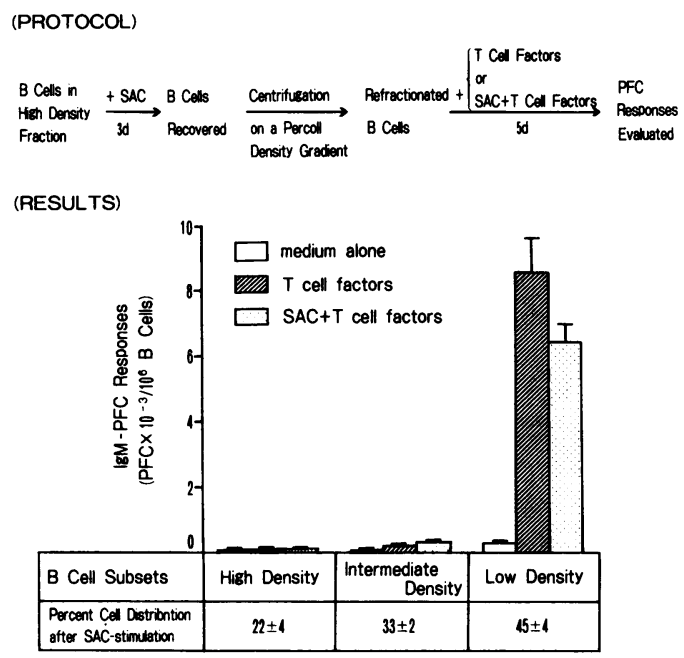

Figure 4. SAC-induced IgM-PFC responses by Percoll-fractionated B cells after preincubation of $B$ cells sedimenting in a high density fraction on Percoll for $3 \mathrm{~d}$ with SAC. B cells that had sedimented in a high density fraction on the Percoll gradients were stimulated for $3 \mathrm{~d}$ with SAC $(0.002 \%$ vol/vol) and refractionated by the Percoll density gradients. Refractionated cells were then tested on their differentiation responses by SAC $(0.002 \% \mathrm{vol} / \mathrm{vol})$ and/or T cell-derived soluble factors $(40 \% \mathrm{vol} / \mathrm{vol})$. The results are shown as the mean PFC responses $+\mathrm{SE}$ of four separate experiments using four different normal donors.
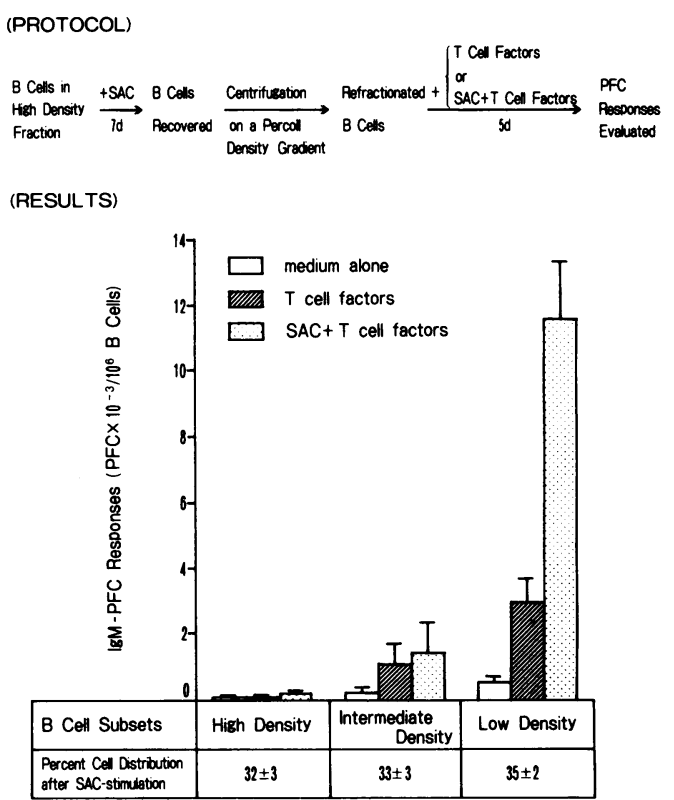

Figure 5. SAC-induced IgM-PFC responses by Percoll-fractionated B cells after preincubation of $B$ cells sedimenting in a high density fraction on Percoll for $7 \mathrm{~d}$ with SAC. Experimental procedures were those of Fig. 3 except that high density B cells were preincubated for $7 \mathrm{~d}$ with SAC. The results are shown as the mean PFC responses $+\mathrm{SE}$ of seven separate experiments from seven different normal donors.

$>4,000$ of PFC should appear from the high density B cells recovered from circulating $B$ cells. Nevertheless, these high density B cells did generate only $<1,000$ PFC in response to SAC plus T cell factors (Fig. 3, and Tables II and III). Also, relevant are findings demonstrating that after refractionation of SAC-stimulated high density B cells for 3 or $7 \mathrm{~d}$ on Percoll density gradients, refractionated high density $B$ cells, intermediate density B cells, and low density B cells were combined at a 2:3:5 or 3:3:4 ratio, respectively. These cell mixtures were recultured for another $5 \mathrm{~d}$ in the presence of $\mathrm{T}$ cell factors alone (for the former cell mixtures) or SAC plus $\mathrm{T}$ cell factors (for the latter cell mixtures) and PFC responses were measured; only $<2,000$ PFC were developed in both types of the cell mixtures (data not shown). Possible explanation for these results are that high enough cell density of $B$ cells that can be easily driven to become Ig-secreting cells (B cells with low density) and cell-to-cell interactions among them are needed to generate maximal PFC responses.

Of particular interest that emerged from the above experiments is the fact that SAC-stimulation could induce differentiation of two discrete $B$ cell subsets via two distinct activation pathways: small, high density resting (preproliferated) B cells are induced by SAC to proliferate (Fig. 1), and the proliferating cells are in turn stimulated to secrete $\mathrm{Ig}$ in response to $\mathrm{T}$ cell factors (Fig. 4); large, low density resting (postproliferated) B cells are stimulated by SAC in presence of $T$ cell factors to differentiate into Ig-secreting cells without active proliferation (Figs. 3 and 5).

\section{Discussion}

The present study demonstrates a functional heterogeneity in human peripheral blood B lymphocytes. By using density gra- 
dient separation techniques, human peripheral blood B lymphocytes can be divided into at least two fractions based on their differential ability at replication and differentiation into Ig-secreting cells in response to SAC and/or T cell factors. Small, high density resting B cells preferentially proliferate in response to SAC with subsequent poor differentiation into Igsecreting cells even in presence of $T$ cell factors; in contrast, large, low density resting $\mathrm{B}$ cells appear to lack proliferation when stimulated with SAC, nevertheless they are induced by $\mathrm{SAC}$ in presence of $\mathrm{T}$ cell factors to produce Ig. These distinct functional properties are not due to complete depletion of monocytes because adding back of monocyte to cultures of the high density and low density B cells results in neither differentiation of the former cells nor proliferation of the latter cells (Table III). The experiments using DNA synthesis inhibitor Ara-C further indicate that active proliferation is not an obligatory prerequisite for maturation of the low density B cells to Ig-secreting cells. Similar results regarding the functional heterogeneity of density-separated B cells have been also reported in murine systems as well as human systems (46-49).

With regard to characteristics of intermediate density $B$ cells, it remains to be elucidated whether they constitute a unique subset that can be distinguished from the high and low density B cell subsets, or alternatively, whether they are simply a combined subset of these two subsets. Considering differential sensitivity to Ara-C in the intermediate density $B$ cells and either low or high density B cells, it is possible that intermediate density B cells are functionally different from other B cell subsets. Experiments to further address this issue are currently under investigation.

In accordance with our findings, some subsets of human B cells have been described to differentiate into Ig-secreting cells without cell division $(20,21,24,25,27-31)$. Necker et al. showed that in humans an antibody against transferrin receptors that blocks cell division can not completely block in vitro Ig production of $B$ cells induced by protein $A$ and $T$ cell factors (24). Further, previous reports from Andersson and Melchers have suggested that although resting murine B cells (isolated on the basis of cell density) can not proliferate in response to B cell replication and maturation factors, they can differentiate directly into Ig-secreting cells without the need for cell division (22). BCL1 cells are also known to be capable of secreting Ig after activation, in absence of cell division $(18,26)$.

The conflicting views regarding the point whether cell division is essential for the induction of Ig secretion may reflect the differential subsets of resting $B$ cells triggered in in vitro system. After activation, resting B cells located in a preproliferated state must first proliferate before differentiation (i.e., cells sedimenting in a fraction of high density B cells), whereas resting $B$ cells located in a postproliferated state must be stimulated to directly differentiate into Ig-secreting cells without the need for proliferation (i.e., cells sedimenting in a fraction of low density B cells). To support the existence of the latter cells, we indeed found that $B$ cells sedimenting into the low density fraction (which marginally respond in proliferation to SAC stimulation) can differentiate into Ig-secreting cells in response to SAC plus $\mathrm{T}$ cell factors even in presence of Ara-C. With regard to the existence of the former cells, $B$ cells that have been moved to a fraction of low density B cells by SAC-stimulation of high density $B$ cells for $7 \mathrm{~d}$ and have reverted to resting state can differentiate into Ig-secreting cells in response to SAC plus $\mathrm{T}$ cell factors. The results presented here suggest that previous analysis on the relation of cell replication to differentiation using whole $B$ cells or B cell clones should be reconsidered in view of the $B$ cell subpopulations as defined by their activation stages.

We have also demonstrated in this paper that B cells in a low density fraction were inducible from $B$ cells in a high density fraction with in vitro stimulation of SAC. The results indicate that both human B cells in the high density fraction and those in the low density fraction belong, at least in part, to the same cell lineage. Some of B cells in the high density fraction could be activated by SAC to be moved to less dense fractions; the low density $B$ cells in the cell cycle progression (i.e., low density B cells after incubation of high density B cells with SAC for $3 \mathrm{~d}$ ) can differentiate into Ig-secreting cells in presence of $\mathrm{T}$ cell factors alone and do not require restimulation with SAC for their differentiation. Low density B cells that have already reverted to and reaccumulated in resting $B$ cells (i.e., low density B cells derived from high density B cells stimulated for $7 \mathrm{~d}$ with SAC) never differentiate into Ig-secreting cells in response to $\mathrm{T}$ cell factors alone; stimulation with SAC and T cell factors are necessary for their differentiation. Thus, responsiveness patterns of in vitro induced low density $B$ cells from SAC-stimulated high density $B$ cells for $7 \mathrm{~d}$ appear to be quite similar to those of freshly isolated low density $B$ cells. The results presented here could explain, at least in part, the previous observations that the high density $B$ cells make a very small but detectable PFC response (Fig. 3 and Table II).

Although SAC has been thought to be a pure B cell mitogen that can stimulate small, resting B cell populations to undergo proliferation and, when provided with adequate $T$ cellderived soluble factors, stimulate the same resting B cell populations to secrete $\operatorname{Ig}(33,39)$, the present study provides evidence that SAC can indeed induce differentiation of two discrete B cell subpopulations via two distinct activation pathways: small, preproliferated resting $B$ cells are induced by SAC-stimulation to differentiate into Ig-secreting cells through vigorous proliferation step; on the contrary, large, postproliferated resting $B$ cells can differentiate without replication in response to SAC and T cell factors. Therefore, the usual measure via SAC-induced proliferation and differentiation for evaluation of $B$ cell function could represent a function of genuine resting $B$ cells (located in a preproliferated state) and that of partially activated B cells (located in a postproliferated state), respectively. Moreover, this proposition that high and low density B cells belong in genuine resting $B$ cells and partially activated B cells, respectively, may be further supported by difference in the ratio of $\operatorname{IgM}^{+} \mathrm{IgD}^{-} / \mathrm{IgM}^{+} \mathrm{IgD}^{+}$between the high and low density $B$ cells. The increase in $\mathrm{IgM}^{+} / \mathrm{IgD}^{+}$ratio has been considered by Cohen et al. $(50,51)$ and Kuritani et al. (37) to indicate advanced B cell maturity because lipopolysaccharide-activated murine B cells display a similar characteristic (51) and human $B$ cells responsive to pokeweed mitogen that is considered to act on partially activated B cells belong to a surface $\mathrm{IgD}^{-}$subpopulation (37). Therefore, the increased ratio of surface $\mathrm{IgM}^{+} \mathrm{IgD}^{-} / \mathrm{IgM}^{+} \mathrm{IgD}^{+}$in the low density $\mathrm{B}$ cells indicates that although they belong in the resting B cells, they must be located in partially activated status. The high density B cells that bear $\operatorname{IgM}^{+} \mathrm{IgD}^{+}$on surfaces could be located in genuine resting status.

In summary, $B$ cells localized in certain activation stages could differentiate directly into Ig-secreting cells without proliferation events. Normal human circulating so called "resting 
B cells" could contain, at least in part, such B cells. The dissection of the B cell populations responsible for replication and/or differentiation should provide new insight into the existence of functional subsets of human B cells as well as B cell activation processes. Further clarification of these issues may give an important clue to the pathogenesis of diseases involved in abnormalities of $\mathbf{B}$ cell activation, such as autoimmune diseases, immune deficiencies, and immune aberration associated with aging.

\section{Acknowledgments}

We wish to thank Dr. T. Tsuchiya of Nihon University School of Medicine (Tokyo, Japan) and Dr. T. Uchiyama of Kyoto University School of Medicine (Kyoto, Japan) for providing SAC and anti-Tac antibody, respectively. We are indebted to Ms. H. Horii for help in preparing the manuscript.

This work was supported in part by a 1986-1987 grant in aid for scientific research, project 61570312, from the Ministry of Education, Science, and Culture of Japan and by a 1986 research grant from the Tokyo Biochemical Research Foundation, Tokyo, Japan.

\section{References}

1. Melchers, F., and J. Andersson. 1986. Factors controlling the B-cell cycle. Ann. Rev. Immunol. 4:13-36.

2. Howard, M., and W. E. Paul. 1983. Regulation of B cell growth and differentiation by soluble factors. Ann. Rev. Immunol. 1:307-333.

3. Kishimoto, T. 1985. Factors affecting B-cell growth and differentiation. Ann. Rev. Immunol. 3:135-159.

4. Muraguchi, A., J. H. Kehrl, and A. S. Fauci. 1985. Activation, proliferation, and differentiation of human B lymphocytes. Lymphokines. 10:33-56.

5. Waldmann, T. A., and S. Broder. 1982. Polyclonal B-cell activators in the study of the regulation of immunoglobulin synthesis in the human system. Adv. Immunol. 32:1-63.

6. Yoshizaki, K., T. Nakagawa, T. Kaieda, A. Muraguchi, Y. Yamamura, and T. Kishimoto. 1982. Induction of proliferation and Ig production in human B leukemic cells by anti-immunoglobulins and T cell factors. J. Immunol. 128:1296-1301.

7. Boyd, A. W., K. C. Anderson, A. S. Freedman, D. C. Fisher, B. Slaughenhoupt, S. F. Schlossman, and L. M. Nadler. 1985. Studies of in vitro activation and differentiation of human B lymphocytes. I. Phenotypic and functional characterization of the B cell population responding to anti-Ig antibody. J. Immunol. 134:1516-1523.

8. Romagnani, S., M. G. Giudizi, R. Biagiotti, F. Almerigogna, E. Maggi, G. Del Prete, and M. Ricci. 1981. Surface immunoglobulins are involved in the interaction of protein $A$ with human $B$ cells and in the triggering of $\mathrm{B}$ cell proliferation induced by protein A-containing Staphylococcus aureus. J. Immunol. 127:1307-1313.

9. Falkoff, R. J. M., L. P. Zhu, and A. S. Fauci. 1982. Separate signals for human $B$ cell proliferation and differentiation in response to Staphylococcus aureus: evidence for a two-signal model of B cell activation. J. Immunol. 129:97-102.

10. Howie, S., and W. H. McBride. 1982. Cellular interactions in thymus-dependent antibody responses. In B Lymphocytes Today. J. R. Inglis, editor. Elsevier Biomedical Press, Amsterdam/New York/ Oxford. 49-54.

11. Julis, M. H. 1982. Cellular interactions in T-dependent B-cell activation. In B Lymphocytes Today. J. R. Inglis, editor. Elsevier Biomedical Press, Amsterdam/New York/Oxford. 55-58.

12. Andersson, J., and F. Melchers. 1981. T cell-dependent activation of resting B cells: requirement for both nonspecific unrestricted and antigen-specific Ia-restricted soluble factors. Proc. Natl. Acad. Sci. USA. 78:2497-2501.

13. Muraguchi, A., J. L. Butler, J. H. Kehrl, and A. S. Fauci. 1983.
Differential sensitivity of human B cell subsets to activation signals delivered by anti- $\mu$ antibody and proliferative signals delivered by a monoclonal B cell growth factor. J. Exp. Med. 157:530-546.

14. Swain, S. L., G. D. Wetzel, and R. W. Dutton. 1985. B cell growth and differentiation factors. Lymphokines. 10:1-14.

15. Kishimoto, T., K. Yoshizaki, M. Kimoto, M. Okada, T. Kuritani, H. Kuritani, K. Shimizu, N. Nakagawa, Y. Miki, H. Kishi, K. Fukunaga, T. Yoshikubo, and T. Taka. 1984. B cell growth and differentiation factors and mechanism of B cell activation. Immunol. Rev. 78:97-118.

16. Jelinek, D. F., and P. E. Lipsky. 1985. The role of T cell factors in activation, cell cycle progression, and differentiation of human B cells. J. Immunol. 134:1690-1701.

17. Jelinek, D. F., and P. E. Lipsky. 1983. The role of B cell proliferation in the generation of immunoglobulin-secreting cells in man. J. Immunol. 130:2597-2604.

18. Simpson, L. G., and P. C. Isakson. 1986. Role of DNA synthesis in secretion of immunoglobulin from murine B cells stimulated by T cell derived lymphokines. J. Immunol. 137:1797-1802.

19. Swain, S. L., M. Howard, J. Kappler, P. Marrack, J. Watson, R. Booth, G. D. Wetzel, and R. Dutton. 1983. Evidence for two distinct classes of murine $B$ cell growth factors with activities in different functional assays. J. Exp. Med. 158:822-835.

20. Chen, W.-Y., J. Muńoz, H. H. Fudenberg, E. Tung, and G. Virella. 1981. Polyclonal activation of human peripheral blood B lymphocytes by formaldehyde-fixed Salmonella Paratyphi B. I. Immunoglobulin production without DNA synthesis. J. Exp. Med. 153:365374.

21. Grayson, J., N. J. Dooley, I. R. Koski, and R. M. Blaese. 1981. Immunoglobulin production induced in vitro by glucocorticoid hormones: $T$ cell-dependent stimulation of immunoglobulin production without B cell proliferation in cultures of human peripheral blood lymphocytes. J. Clin. Invest. 68:1539-1547.

22. Melchers, F., J. Andersson, W. Lernhardt, and M. H. Schreier. 1980. H-2-unrestricted polyclonal maturation without replication of small B cells induced by antigen-activated T cell help factors. Eur. $J$. Immunol. 10:679-685.

23. Sidman, C. L., and J. D. Marshall. 1984. B cell maturation factor: effects on various cell populations. J. Immunol. 132:845-850.

24. Necker, L. M., G. Yenokida, and S. P. James. 1984. The role of the transferrin receptor in human B lymphocyte activation. J. Immunol. 133:2437-2441.

25. Ito, S., and A. R. Lawton. 1984. Response of human B cells to Staphylococcus aureus Cowan I: T-independent proliferation and Tdependent differentiation to immunoglobulin secretion involve subsets separable by rosetting with mouse erythrocytes. J. Immunol. 133:1891-1895.

26. Isakson, P. C., E. Puré, J. W. Uhr, and E. S. Vitetta. 1981. Induction of proliferation and differentiation of neoplastic $B$ cells by anti-immunoglobulin and T-cell factors. Proc. Natl. Acad. Sci. USA. 78:2507-2511.

27. Tomita, S., J. L. Ambrus, Jr., D. J. Volkman, D. L. Longo, H. Mitsuya, M. S. Reitz, Jr., and A. S. Fauci. 1985. Human T cell leukemia/lymphoma virus I infection and subsequent cloning of normal human B cells: direct responsiveness of cloned cells to recombinant interleukin 2 by differentiation in the absence of enhanced proliferation. J. Exp. Med. 162:393-398.

28. Fu, S. M., N. Chiorazzi, H. G. Kunkel, J. H. Halper, and S. R. Harris. 1978. Induction of in vitro differentiation and immunoglobulin synthesis of human leukemic B lymphocytes. J. Exp. Med. 148:1570-1578.

29. Mayer, L. 1986. Terminal maturation of resting B cells by proliferation-independent B cell differentiation factors. J. Exp. Med. 164:383-392.

30. Muraguchi, A., T. Kishimoto, Y. Miki, T. Kuritani, T. Kaieda, K. Yoshizaki, and Y. Yamamura. 1981. T cell-replacing factor-(TRF) induced IgG secretion in a human B blastoid cell line and demonstration of acceptors for TRF. J. Immunol. 127:412-416. 
31. Parker, D. C. 1982. Separable helper factors support B cell proliferation and maturation to Ig secretion. J. Immunol. 129:469474.

32. Suzuki, N., T. Sakane, Y. Ueda, Y. Murakaiwa, and T. Tsunematsu. 1986. Implications for the role of cognate interactions in in vitro human B cell activation by Staphylococcus aureus Cowan I and pokeweed mitogen. J. Clin. Invest. 77:294-300.

33. Sakane, T., Y. Ueda, N. Suzuki, Y. Niwa, T. Hoshino, and T. Tsunematsu. 1985. OKT4 $4^{+}$and OKT8 ${ }^{+} \mathrm{T}_{\text {lymphocytes produce solu- }}$ ble factors that can modulate growth and differentiation of human $B$ cells. Clin. Exp. Immunol. 62:112-120.

34. Mier, J. W., and R. C. Gallo. 1980. Purification and some characteristics of human T-cell growth factor from phytohemagglutinin-stimulated lymphocyte-conditioned media. Proc. Natl. Acad. Sci. USA. 77:6134-6138.

35. Ruscetti, F. W., and R. C. Gallo. 1981. Human T-lymphocyte growth factor: regulation of growth and function of $\mathrm{T}$ lymphocytes. Blood. 57:379-394.

36. Dagg, M. K., and D. Levitt. 1981. Human B-lymphocyte subpopulations. I. Differentiation of density-separated B lymphocytes. Clin. Immunol. Immunopathol. 21:39-49.

37. Kuritani, T., and M. D. Cooper. 1982. Human B cell differentiation. II. Pokeweed mitogen-responsive B cells belong to a surface immunoglobulin D-negative subpopulation. J. Exp. Med. 155:15611566.

38. Gronowicz, E., A. Coutinho, and S. F. Melchers. 1976. A plaque assay for all cells secreting Ig of a given type or class. Eur. $J$. Immunol. 6:588-590.

39. Suzuki, N., T. Sakane, Y. Ueda, and T. Tsunematsu. 1986. Abnormal B cell function in patients with Behçet's disease. Arthritis Rheum. 29:212-219.

40. Muraguchi, A., J. H. Kehrl, D. L. Longo, D. J. Volkman, K. A. Smith, and A. S. Fauci. 1985. Interleukin 2 receptors on human B cells: implications for the role of interleukin 2 in human B cell function. J. Exp. Med. 161:181-197.

41. Calabresi, P., and P. E. Park, Jr. 1980. Antiproliferative agents and drugs used for immunosuppression. In The Pharmacological Basis of Therapeutics. 6th ed. A. G. Gilman, L. S. Goodman, and A. Gilman, editors. Macmillan Publishing Co., New York. 1256-1313.
42. Waldmann, T. A, C. K. Goldman, R. J. Robb, J. M. Depper, W. J. Leonard, S. O. Sharrow, K. F. Bongiovanni, S. J. Korsmeyer, and W. C. Greene. 1984. Expression of interleukin 2 receptors on activated human B cells. J. Exp. Med. 160:1450-1466.

43. Haynes, B. F., M. Hemler, T. Cotner, D. L. Mann, G. S. Eisenbarth, J. L. Strominger, and A. S. Fauci. 1981. Characterization of a monoclonal antibody (5E9) that defines a human cell surface antigen of cell activation. J. Immunol. 127:347-351.

44. Vindeløv, L. L. 1977. Flow microfluorometric analysis of nuclear DNA in cells from solid tumors and cell suspension: a new method for rapid isolation and staining of nuclei. Virchows Arch. B Cell Pathol. 24:227-242.

45. Lipsky, P. E. 1985. Role of interleukin-1 in human B-cell activation. In Contemporary Topics in Molecular Immunology. S. Gillis and F. P. Inman, editors. Plenum Publishing Corp., New York. 195-217.

46. Thompson, C. B., I. Scher, M. E. Schaefer, T. Lindsten, F. D. Finkelman, and J. J. Mond. 1984. Size-dependent B lymphocyte subpopulations: relationship of cell volume to surface phenotype, cell cycle, proliferative response, and requirements for antibody production to TNP-Ficoll and TNP-BA. J. Immunol. 133:2333-2342.

47. Mosier, D. E. 1986. T cell activation of antigen-specific antibody responses by large B cells is MHC restricted. J. Immunol. 136:2090-2094.

48. Maruyama, S., H. Kubagawa, and M. D. Cooper. 1985. Activation of human $B$ cells and inhibition of their terminal differentiation by monoclonal anti- $\mu$ antibodies. J. Immunol. 135:192-199.

49. Richard, Y., C. Leprince, D. Treton, and P. Galanaud. 1986. Functional heterogeneity of nonresting B cells in human blood. Eur. $J$. Immunol. 16:1303-1308.

50. Cohen, P., M. Ziff, and E. S. Vitetta. 1978. Characterization of $B$ cell defect in the NZB mouse manifested by an increased ratio of surface IgM to IgD. J. Immunol. 121:973-977.

51. Bourgois, A., K. Kitajima, I. R. Hunter., and B. A. Askonas. 1977. Surface immunoglobulins of lipopolysaccharide-stimulated spleen cells: the behavior of IgM, IgD and IgG. Eur. J. Immunol. 7:151-153. 